\title{
Alteration in corneal astigmatism and tear stability in patients undergoing surgical excision of ptreygium- a prospective study undertaken in a tertiary centre in south Kerala
}

\author{
Jasmine Mary Jacob ${ }^{1}$, Susan Kurian ${ }^{2}$, Sheldon J Goudinho ${ }^{3, *}$ \\ ${ }^{1}$ Professor, ${ }^{2}$ Post Graduate, ${ }^{3}$ HOD and Prof, Dept. of Ophthalmology, Dr Somervell Memorial CSI Medical College, Karakonam, \\ Kerala
}

*Corresponding Author:

Email: sheldonjasmine@gmail.com

\begin{abstract}
Alterations in corneal astigmatism and tear stability in patients undergoing surgical excision of pterygium: a prospective study undertaken in a tertiary centre in south Kerala.

Objective: To analyse the effect of surgical intervention on corneal astigmatism \& tear stability in patients with ptreygium. Methodology: In this prospective observational study conducted in ophthalmology department, Dr. SMCSI Medical College, Karakonam, 39 eyes with primary pterygium enrolled between January 2016 to May 2017 for pterygium excision with conjunctival autograft, were analysed. Preoperatively and one month post operative. Uncorrected \& best corrected visual acuity, keratometry readings (K1, K2) was recorded. Pterygia were graded as grade I, II, III \& IV.TBUT and Schirmer's test used to measure tear function. Descriptive measures were calculated using percentage or mean (SD). Pre-operative and post-operative difference in values of astigmatism and tear function tests were assessed using test of significance, paired t-test.

Results: Of the patients enrolled with primary pterygium, 56.4\% (22) were females and 43.6\% (17) males. $42 \%$ had right eye ptreygium and $58 \%$ in the left. 84.3\%(33) were nasal, $12.8 \%$ (5) temporal and $2.6 \%(1)$ double pterygium. 76.9 \%( 30) were grade II, $10.3 \%$ (4) grade III, $12.8 \%$ (5) grade IV. There was a reduction in astigmatism from $2.29+/-1.4 \mathrm{D}$ to $1.02+/-0.74 \mathrm{D}$ $(\mathrm{p}<0.001)$. However, the alteration in preoperative and post operative tear function tests was insignificant.

Conclusion: Surgical intervention proved beneficial for patients with pterygium in terms of reduction of refractive astigmatism. A statistically significant change was not observed in tear function.
\end{abstract}

Keywords: Astigmatism, Conjunctival autograft, Ptreygium, Tear function.

\section{Introduction}

Ptreygium is a wing shaped fold of fibro vascular tissue that arises from the interpalpebral conjunctiva which may encroach onto the cornea. ${ }^{1-2}$ Prevalence rates for ptreygium are seen to change from place to place, ${ }^{3-8}$ and are more common within 300 above and below the equator, making it fairly common in India, which is located within the tropics. ${ }^{2}$ An epidemiological study undertaken in one of the tropical islands in the Indonesian archipelago, revealed the overall prevalence rate of ptreygium to be $17 \%,{ }^{9}$ and the prevalence was as high as $11.7 \%$ in a recent population based study conducted in Andhra Pradesh. ${ }^{10}$

Although ptreygium continues to be an enigma and various theories have been postulated regarding its origin, one of the current beliefs is that ptreygium is a growth disorder characterized by conjunctivalisation of the cornea due to localized ultraviolet induced damage to the limbal stem cells. ${ }^{11-12}$ Ultraviolet light and environmental factors do play an important role in the pathogenesis of ptreygium but interestingly only some people, not all, living under the same conditions develop ptreygium, suggesting role for other factors as well. Inadequate tear film stability in Pterygia patients has been documented by Kadayifcilar ${ }^{13}$ and Ishioka ${ }^{14}$ in their study on changes in tear film after primary ptreygium excision, suggesting that abnormal tear function may be, yet another risk factor related to ptreygium development. However, in a more recent study on Tear function and goblet cell density after ptreygium excision, $\mathrm{Li} \mathrm{M}$ et al, have been able to demonstrate that it is the ptreygium that alters the tear film and not the other way round. ${ }^{15}$

The commonly accepted treatment for ptreygium is its excision and multiple surgical approaches have been developed over the years. Surgery is undertaken either when the ptreygium threatens the visual axis, induces corneal astigmatism, causes irritation and inflammation and for cosmesis. ${ }^{1-2}$

Pterygia are notorious in distorting the corneal contour thereby disturbing the visual axis and causing astigmatism. It has been suggested that the ptreygium induces astigmatism by various mechanisms. These include (a) mechanical traction exerted by the ptreygium on cornea, (b) pooling of the tear film at the leading edge of the pterygium. ${ }^{16-18}$ Ptreygium-induced astigmatism can be the cause of subjective visual complaints, including decreased visual acuity, glare sensitivity and monocular diplopia. ${ }^{19}$ Rana, AltanYaycioglu et al, in their study comparing astigmatic changes using 5 techniques for excision of ptreygium, concluded that irrespective of which technique is being used, successful surgical excision results in reduction of corneal astigmatism to an acceptable level. ${ }^{20}$

It is known that pterygium exert mechanical traction onto the cornea there by distorting its surface 
and inducing corneal astigmatism. Pterygium has also been closely linked with tear film instability. Though common $30^{\circ}$ above and below the equator, making it common in India, published Indian studies on the effect of ptreygium on astigmatism and tear function are limited.

\section{Objective}

To analyse the effect of surgical intervention on corneal astigmatism \& tear stability in patients with pterygium.

\section{Materials and Methods}

Study Design: Descriptive (prospective observational). Study Setting: Ophthalmology department of Dr. SMCSI Medical College, Karakonam, Thiruvananthapuram.

Study Period: January 2016 to May 2017.

Tools Used: Snellen's chart with trial set, autokeratorefractometer (Topcon Kr 8800), streak retinoscope, slit lamp bio-microscope (Zeiss), fluorescein sodium strip for measuring the tear film break up time (TBUT) and Schirmer's tear test strips for the Schirmer's test were tests for analyzing the tear function, Proforma: patient data vital to the study will be entered by the examiner.

Study Population: All patients visiting the Ophthalmology outpatient department.

Inclusion Criteria: Patients above 20yrs of age with ptreygium, willingness for surgery.

Exclusion Criteria: Ocular pathologies like cataract, glaucoma or retinal disease that have an effect on their visual acuity, other corneal pathology causing corneal astigmatism, prior ocular surgeries within last 2 months, Extensive contact lens wear, pemphigoid, Sjögren's syndrome, and conditions causing dry eye.

Data Collection: Tools \& technique: a semi-structured questionnaire was utilized for entry of data. Patients underwent a comprehensive eye examination preoperatively and one month post operatively. This comprised visual acuity assessment both uncorrected (UCVA) and best corrected (BCVA) using Snellen's Chart for distant vision, wet streak retinoscopy and Auto Refractometer (AR). Astigmatism measurement as cylindrical correction obtained based on subjective and objective refraction. Keratometric values K1, K2 using auto keratometer. Slit lamp biomicroscope for anterior segment, pterygium grading and dilated fundus examination. Pterygia were graded accordingly: Grade I (crossing limbus), Grade II (midway between limbus and pupil), Grade III (reaching up to pupillary margin) Grade IV (crossing pupillary margin)

Tear function evaluation: Tear film break-up time measurement with fluorescein and the Schirmer test without topical anaesthesia was performed. The Schirmer test result was expressed as the wet length of the Schirmer strip measured after 5 minutes when inserted on the junction of middle and outer $3^{\text {rd }}$ of lower lid and expressed in millimetres (less than $10 \mathrm{~mm}$ of wetting after 5 minutes was considered abnormal).

Surgical procedure. Patients underwent pterygium excision with CAG (conjunctival autografting).The head and cap of the ptreygium grasped with Collibri's forceps and ptreygium dissected from the cornea up to the limbus. Subconjunctival pterygium tissue and superficial conjunctiva in the area of the head of the pterygium excised. Superficial conjunctiva in the superotemporal area of the eye ball is raised with a subconjunctival injection of saline and conjunctival graft of the appropriate size to cover the scleral defect will be cut out. The graft placed on the area of the bare sclera and anchored using 10-0 nylon sutures.

Data Analysis: Statistical data were entered into excel sheet and was analyzed using SPSS version 22. Descriptive measures were calculated using percentage or mean (SD). Pre-operative and post-operative difference in values of astigmatism and Tear Function tests were assessed using test of significance, paired ttest.

\section{Results}

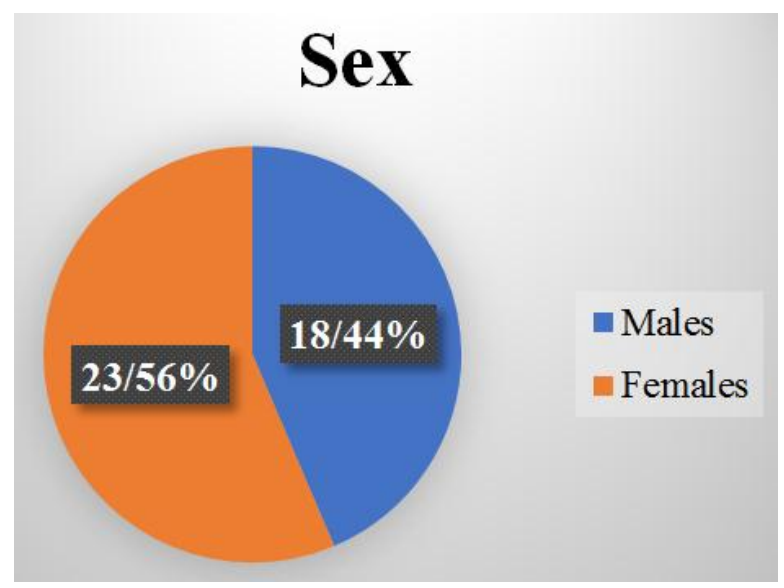

Fig. 1: Male to female ratio

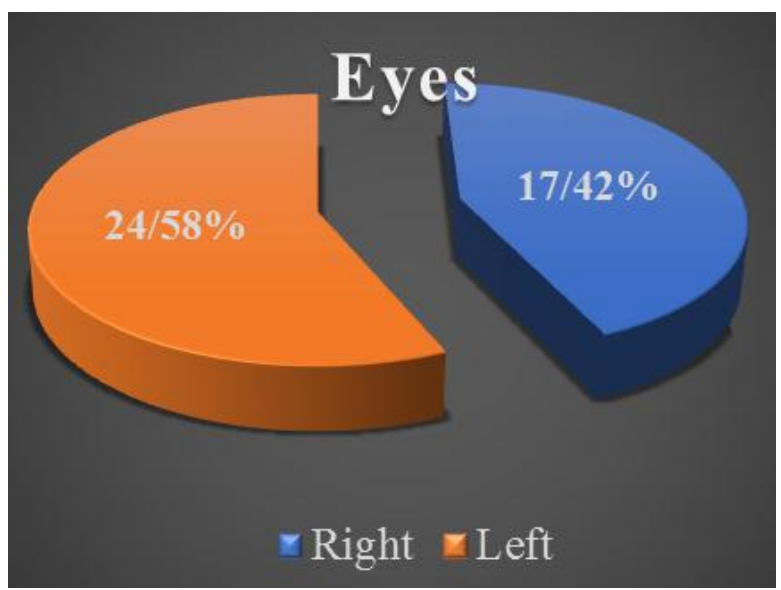

Fig. 2: Laterality 

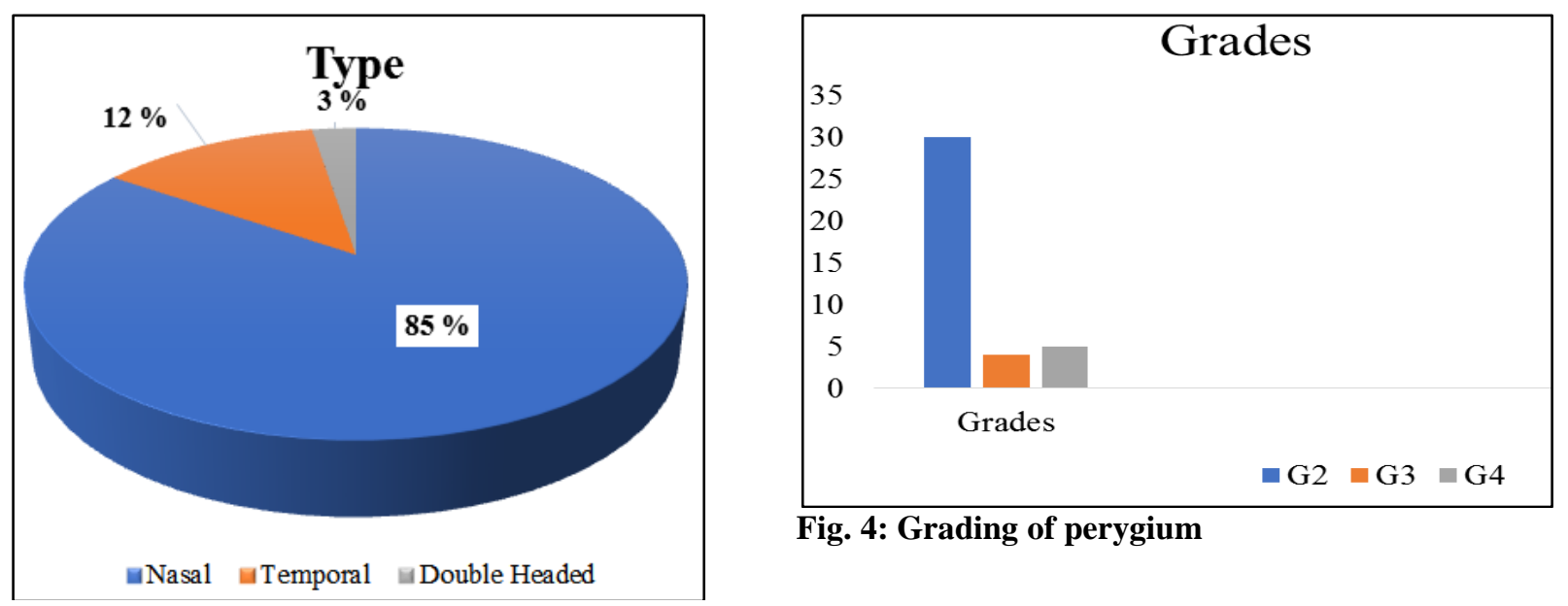

Fig. 4: Grading of perygium

Fig. 3: Nasal/ temporal/double ptreygium

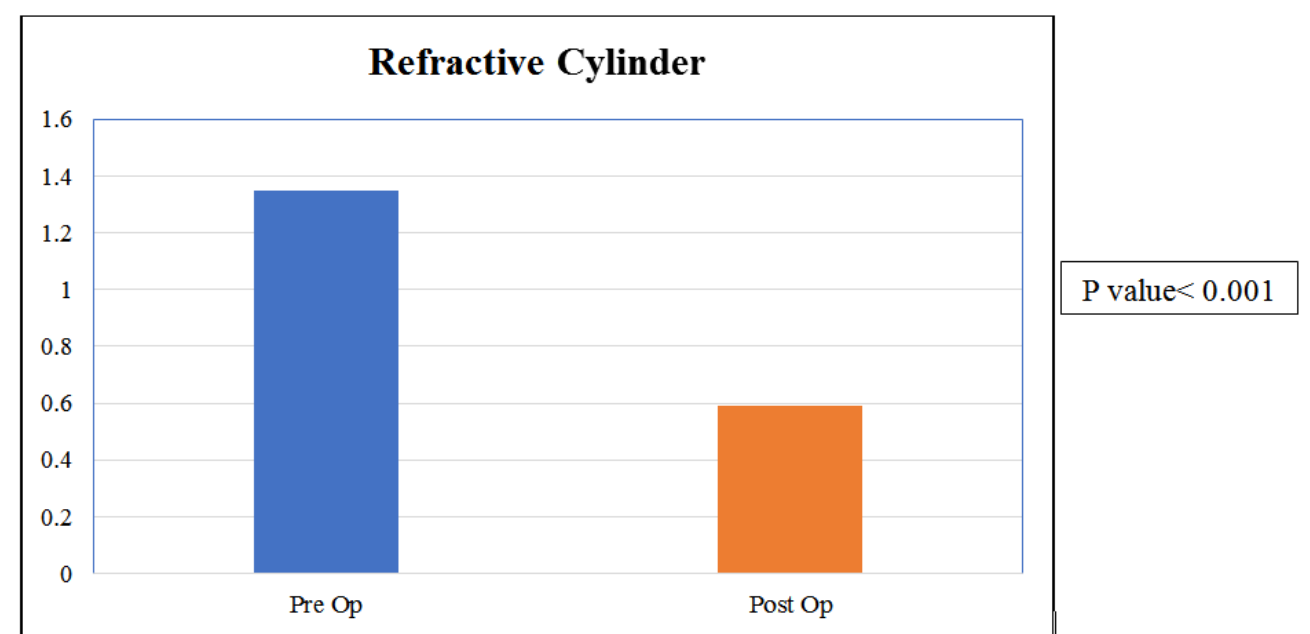

Fig. 5: Reduction in refractive cylinder following surgery

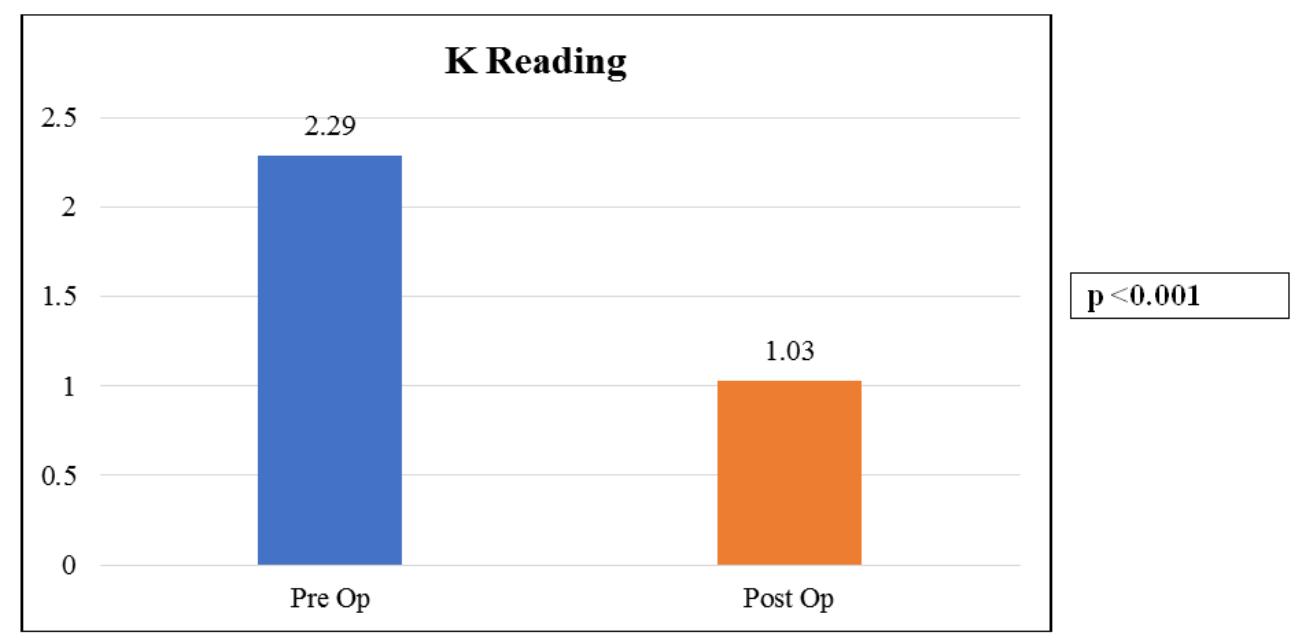

Fig. 6: The reduction in keratometric value following surgery 

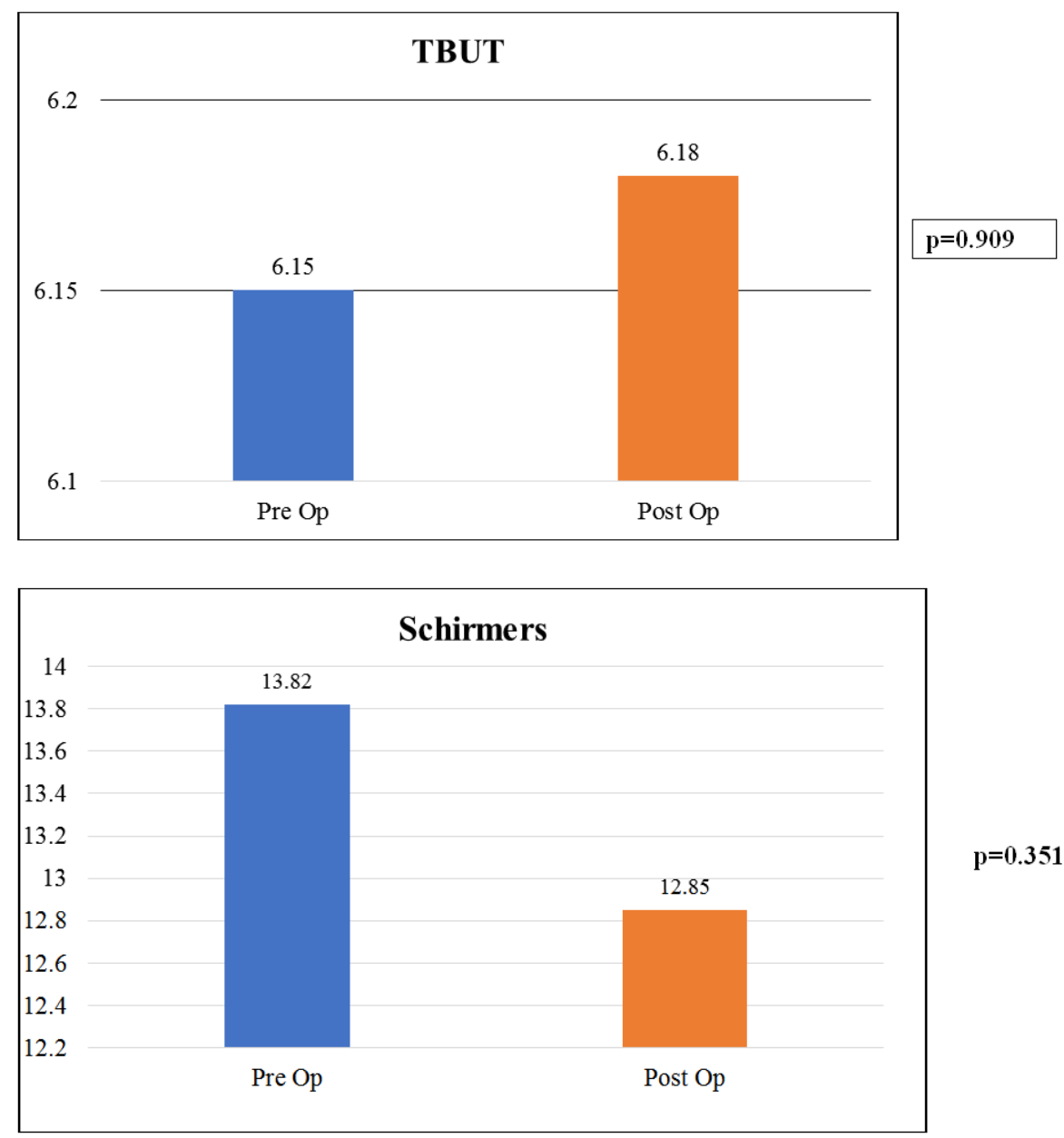

Fig. 7: Change in TBUT following surgery

\section{Discussion}

Pterygium is known to distort the corneal contour and thereby disturb the visual axis and causing astigmatism. It has been suggested that the pterygium induces astigmatism by various mechanisms like exerting mechanical traction on the cornea and pooling of the tear film at the leading edge of the pterygium.

Pterygium induced astigmatism can be the cause of subjective visual complaints, including decreased visual acuity, glare sensitivity and monocular diplopia.

The present study was able to demonstrate a statistically significant reduction in refractive cylinder following excision. The mean pre operative refractive cylinder was $1.34 \mathrm{D}$ which reduced to $0.58 \mathrm{D}$ post operatively $(\mathrm{p}<0.001)$.

This followed a similar trend to the following Indian Studies.

S. Maheshwari et al: preoperative refractive cylinder was $4.60 \pm 2 \mathrm{D}$, which improved to $2.20 \pm 2.04$ D. ${ }^{18}$

R. Kujur et al: The mean preoperative refractive cylinder decreased from $3.29 \pm 1.46 \mathrm{D}$ to $1.49 \pm 0.82 \mathrm{D}$ postoperatively. ${ }^{22}$
Rana Altan et al: Preoperatively, the mean astigmatic value was $3.47 \pm 2.50 \mathrm{D}$ decreased to $1.29 \pm$ $1.07 \mathrm{D}^{5}$

However, a similar pattern could not be established with regard to tear film stability.

Despite extensive literature review, similar studies from India examining the effect of pterygium on tear functionality were not found. Stating below international studies conducted with this regard.

Kadayifcilar et al (1998): 70 eyes; case control study (cases=patients with ptreygium; controls: healthy subjects)- showed significant alteration in the case group. ${ }^{1}$

Ergin a et al (2001): 84 eyes; case-control study; were not able to show any difference in tear function between cases and controls. ${ }^{21}$

M.Li et al (2007): 70 eyes with primary pterygia underwent a bare-sclera procedure. TBUT, Schirmer's, and tear-ferning tests and conjunctival goblet cell density obtained by impression cytology were evaluated before and 1 month after surgery. The TBUT (11.493.76 s) one month after surgery was significantly prolonged compared to the pre operative period (9.743.43 s, $P=0.002)$ but Schirmer values remained unchanged. ${ }^{3,15}$ 
The small sample size, single post-operative evaluation at one month was some of the limitations of this study. Larger sample size and long term follow up would have been more conclusive. Inaccessibility of corneal topography was yet another shortcoming which would have helped in measurement of corneal astigmatism in an improved manner.

\section{Conclusion}

Successful ptreygium surgery reduces the pterygium-induced refractive astigmatism thereby improving visual acuity. On the other hand, a statistically significant change could not be noticed with tear function in the one month post-operative period.

Further follow ups and similar studies will have to be undertaken to confirm or refute our findings.

\section{References}

1. Kadayifcilar SC, Orhan M, Irkec M. Tear functions in patients with pterygium. Acta Ophthalmol Scand 1998;76:176-179.

2. Ishioka M, Shimmura S, Yagi Y, Tsubota K. Pterygium and dry eye. Ophthalmologica 2001;215:209-211.

3. M Li1,2, M Zhang1, Y Lin et al; Tear function and goblet cell density after pterygium excision; Eye (2007) 21, 224-228.

4. Sejal Maheshwari MS; Effect of Pterygium Excision on Pterygium Induced Astigmatism; IJO June 2003; vol 51 no 2, 187-188.

5. Rana Altan-Yaycioglu et al Astigmatic changes following pterygium removal: Comparison of 5 different methods; Indian Journal of Ophthalmology; Vol. 61 No. 3 105107.

6. Avisar R, Mekler S, Savir H. Effect of pterygium excision on keratometric readings. Harefuah 1994;126,63:111-12.

7. Rojas JR, Malaga H. Pterygium in Lima, Peru. Annals of ophthalmology. 1986 Apr;18(4):147-9.

8. Wong TY, Foster PJ, Johnson GJ, Seah SK, Tan DT. The prevalence and risk factors for pterygium in an adult Chinese population in Singapore: the Tanjong Pagar survey. American journal of ophthalmology. $2001 \mathrm{Feb}$ 28;131(2):176-83.

9. Tan CS, Lim TH, Koh WP, Liew GC, Hoh ST, Tan CC, Eong KA. Epidemiology of pterygium on a tropical island in the Riau Archipelago. Eye. 2006 Aug 1;20(8):908-12.

10. Marmamula S, Khanna RC, Rao GN. Population-Based Assessment of Prevalence and Risk Factors for Pterygium in the South Indian State of Andhra Pradesh: The Andhra Pradesh Eye Disease Study Pterygium in South IndiaAPEDS. Investigative ophthalmology \& visual science. 2013 Aug 1;54(8):5359-66.

11. Dushku N, Reid TW. Immunohistochemical evidence that human Pterygia originate from an invasion of vimentinexpressing altered limbal epithelial basal cells. Current eye research. 1994 Jan 1;13(7):473-81.

12. Fernandes M, Sangwan VS, Bansal AK, Gangopadhyay N, Sridhar MS, Garg P, Aasuri MK, Nutheti R, Rao GN. Outcome of pterygium surgery: analysis over 14 years. Eye. 2005 Nov 1;19(11):1182-90.

13. Kadayifçilar SÇ, Orhan M, Irkeç M. Tear functions in patients with pterygium. Acta Ophthalmologica. 1998 Apr 1;76(2):176-9.
14. Ishioka M, Shimmura S, Yagi Y, Tsubota K. Ptyerygium and dry eye. Ophthalmologica. 2001;215(3):209-11.

15. Li M, Zhang M, Lin Y, Xiao Q, Zhu X, Song S, Lin J, Chen J, Liu Z. Tear function and goblet cell density after pterygium excision. Eye. 2007 Feb 1;21(2):224-8.

16. Oldenburg JB, Garbus J, McDonnell JM, McDonnell PJ. Mechanism of Corneal Topographic Changes. Cornea. 1990 Jul 1;9(3):200-4.

17. Avisar R, Mekler S, Savir H. Effect of pterygium excision on Keratometric readings. Harefuah. 1994 Jan;126(2):63-5.

18. Maheshwari S. Effect of pterygium excision on pterygium induced astigmatism. Indian journal of ophthalmology. 2003 Jun 1;51(2):187.

19. Lindsay RG, Sullivan L. Pterygium, induced corneal astigmatism. Clinical and Experimental Optometry. 2001 Jul 1;84(4):200-3.

20. Altan-Yaycioglu R, Kucukerdonmez C, Karalezli A, Corak F, Akova YA. Astigmatic changes following pterygium removal: Comparison of 5 different methods. Indian journal of ophthalmology. 2013 Mar;61(3):104.

21. Grayson M. Diseases of the Cornea. CV Mosby; 1979.

22. Nelson JD, Cameron JD. The conjunctiva: anatomy and physiology. Cornea. 2005;1:39-54.

23. Mishima S. Corneal thickness. Surv Ophthalmol. 1968;13:57-96. 